\title{
Subregion-specific modulation of excitatory input and dopaminergic output in the striatum by tonically activated glycine and $\mathrm{GABA}_{A}$ receptors
}

\section{Louise Adermark *, Rhona B. C. Clarke, Mia Ericson and Bo Söderpalm}

Addiction Biology Unit, Department of Psychiatry and Neurochemistry, Institute of Neuroscience and Physiology, University of Gothenburg, Gothenburg, Sweden

\section{Edited by:}

Jose Bargas, Universidad Nacional Autónoma de México, Mexico

Reviewed by:

Zao C. Xu, Indiana University, USA

James W. Grau, Texas A\&M

University, USA

*Correspondence:

Louise Adermark, Addiction Biology Unit, Department of Psychiatry and Neurochemistry, Institute of Neuroscience and Physiology, University of Gothenburg, PO Box 410, 40530 Gothenburg, Sweden. e-mail: louise.adermark@neuro.gu.se
The flow of cortical information through the basal ganglia is a complex spatiotemporal pattern of increased and decreased firing. The striatum is the biggest input nucleus to the basal ganglia and the aim of this study was to assess the role of inhibitory GABA and glycine receptors in regulating synaptic activity in the dorsolateral striatum (DLS) and ventral striatum (nucleus accumbens, nAc). Local field potential recordings from coronal brain slices of juvenile and adult Wistar rats showed that $\mathrm{GABA}_{A}$ receptors and strychninesensitive glycine receptors are tonically activated and inhibit excitatory input to the DLS and to the nAc. Strychnine-induced disinhibition of glutamatergic transmission was insensitive to the muscarinic receptor inhibitor scopolamine $(10 \mu \mathrm{M})$, inhibited by the nicotinic acetylcholine receptor antagonist mecamylamine $(10 \mu \mathrm{M})$ and blocked by $\mathrm{GABA}_{A}$ receptor inhibitors, suggesting that tonically activated glycine receptors depress excitatory input to the striatum through modulation of cholinergic and GABAergic neurotransmission. As an end-product example of striatal GABAergic output in vivo we measured dopamine release in the DLS and $\mathrm{nAc}$ by microdialysis in the awake and freely moving rat. Reversed dialysis of bicuculline $(50 \mu \mathrm{M}$ in perfusate) only increased extrasynaptic dopamine levels in the nAc, while strychnine administered locally (200 $\mu \mathrm{M}$ in perfusate) decreased dopamine output by $60 \%$ in both the DLS and nAc. Our data suggest that $\mathrm{GABA}_{\mathrm{A}}$ and glycine receptors are tonically activated and modulate striatal transmission in a partially subregion-specific manner.

\section{Keywords: basal ganglia, dorsolateral striatum, nucleus accumbens, rat}

\section{INTRODUCTION}

In addition to the control of movements, the basal ganglia are involved in a variety of cognitive and mnemonic functions in the generation and execution of context dependent behaviors (Bolam et al., 2000). The striatum is the biggest input nucleus to the basal ganglia and is innervated by excitatory cortical and thalamic inputs that distribute in dorsomedial-to-ventromedial zones (Nakano et al., 2000; Voorn et al., 2004), and by fibers from midbrain dopamine neurons that regulate reward and rewardguided learning (Voorn et al., 2004; Ikemoto, 2007; Yin et al., 2008; Ikemoto, 2010). Striatal neurons discharge in response to firing of corticostriatal glutamatergic neurons, which leads to inhibition of basal ganglia output neurons and disinhibition (direct) or inhibition (indirect) of neurons in the targets of the basal ganglia. The output of the basal ganglia is thus a complex spatiotemporal pattern of increased and decreased firing, which leads to an inhibitory output signal under resting conditions that is reduced during basal ganglia associated behavior (Chevalier and Deniau, 1990).

Based on the subregion-specific extrinsic connections reaching the striatum and observations from behavioral studies the

Abbreviations: EtOH, ethanol; nAc, nucleus accumbens; VTA, ventral tegmental area. striatal complex can be divided into the dorsal striatum (caudateputamen), which is necessary for the acquisition and expression of instrumental actions, and the nucleus accumbens (nAc), which has been attributed to be important for motivation, reward sensation, and attention (Voorn et al., 2004; Yin and Knowlton, 2004; van Kuyck et al., 2007; Yin et al., 2008; Söderpalm et al., 2009). However, reward-guided learning is not solely controlled by the mesoaccumbens pathway arising from dopaminergic neurons in the ventral tegmental area (VTA) and projecting to the nAc, but also involves the nigrostriatal pathway (Yin et al., 2008; Rushworth et al., 2009).

Even though about $80 \%$ of the synapses in the striatum are asymmetric glutamatergic synapses (Wilson, 2007), the majority of neurons ( $>95 \%$ ) are GABAergic medium spiny projection neurons (MSNs; Tepper et al., 2004). MSNs form a weak lateral inhibitory network among themselves via local axon collaterals (feedback inhibition), while feedforward inhibition by GABAergic interneurons appears to exert a more powerful control of striatal excitability (Tepper et al., 2004). The striatum also contains cholinergic interneurons, which have been implicated in controlling both glutamatergic and GABAergic transmission onto projecting MSNs (Zhou et al., 2002; Pakhotin and Bracci, 2007; Sullivan et al., 2008). Furthermore, strychnine-sensitive glycine 
receptors expressed by cholinergic interneurons have been shown to be involved in regulating extracellular levels of acetylcholine and dopamine (Yadid et al., 1993; Darstein et al., 1997, 2000; Molander and Söderpalm, 2005a,b). Taken together, striatal output is balanced by excitatory and inhibitory neurotransmission (Adermark and Lovinger, 2009), which in turn adjust the flow of cortical information through the basal ganglia and regulate the activity of midbrain dopamine neurons (Söderpalm et al., 2009; Ikemoto, 2010). Changes in dopamine release can in this context be regarded as an in vivo example of how an end-product is influenced by synaptic output from the striatum.

The aim of this study was to assess the role of inhibitory $\mathrm{GABA}_{\mathrm{A}}$ and glycine receptors in regulating striatal neurotransmission. Changes in excitatory input to the striatum were evaluated by field potential recordings conducted in the dorsolateral striatum (DLS) and in the nAc core of acutely isolated brain slices from juvenile and adult Wistar rats. Changes in dopamine output were studied by in vivo microdialysis in awake and freely moving adult Wistar rats.

\section{MATERIALS AND METHODS BRAIN SLICE PREPARATION}

Experiments were carried out in accordance with the guidelines laid down by the Swedish Council regarding the care and use of animals for experimental procedures and were approved by the Ethics Committee for Animal Experiments, Gothenburg, Sweden. Striatal brain slices were prepared from 20- to 23-day-old Wistar rats (Breeding performed at Gothenburg University, rats originating from Charles River, Germany), or adult male Wistar rats (270-350 g; Taconic, Ejby, Denmark). Animals were deeply anesthetized with Isoflurane Baxter (Baxter medical AB, Kista, Sweden) and decapitated. The brains were quickly removed and placed in ice-cold modified artificial cerebrospinal fluid (aCSF) containing (in $\mathrm{mM}$ ); 194 sucrose, $30 \mathrm{NaCl}, 4.5 \mathrm{KCl}, 1 \mathrm{MgCl}_{2}, 26 \mathrm{NaHCO}_{3}$, $1.2 \mathrm{NaH}_{2} \mathrm{PO}_{4}$, and $10 \mathrm{D}$-glucose, bubbled with a mixture of $95 \%$ $\mathrm{O}_{2} / 5 \% \mathrm{CO}_{2}$ gas. After a 5-min equilibration period, the brain tissue was blocked at the anterior and posterior ends and attached with histoacryl (Aesculap \& Co., KG, Tuttlingen, Germany) to a Teflon pad. The tissue was completely submerged into ice-cold modified aCSF and sectioned coronally in $400 \mu \mathrm{m}$ thick slices with a vibrating tissues sectioning system (Campden Instruments Ltd., Loughborough, England). Brain slices were allowed to equilibrate for at least $1 \mathrm{~h}$ at room temperature in normal aCSF containing (in $\mathrm{mM}$ ); $124 \mathrm{NaCl}, 4.5 \mathrm{KCl}, 2 \mathrm{CaCl}_{2}, 1 \mathrm{MgCl}_{2}, 26 \mathrm{NaHCO}_{3}, 1.2$ $\mathrm{NaH}_{2} \mathrm{PO}_{4}$, and $10 \mathrm{D}$-glucose, continuously bubbled with a mixture of $95 \% \mathrm{O}_{2} / 5 \% \mathrm{CO}_{2}$ gas before transferred to the recording chamber.

\section{STRIATAL FIELD POTENTIAL RECORDINGS}

Field potential recordings were performed as previously described (Clarke and Adermark, 2010). In brief, one hemisphere of a slice was transferred to a recording chamber and perfused at a constant rate of $2.6 \mathrm{ml} / \mathrm{min}$ with pre-warmed aCSF kept at $30^{\circ} \mathrm{C}$. Stimulation was delivered as $0.1 \mathrm{~ms}$ negative constant current pulses via a monopolar tungsten electrode (World Precision Instruments, FL, USA, type TM33B), activated at a frequency of $0.05 \mathrm{~Hz}$. Stimulus intensity was set to yield an evoked PS amplitude approximately half the size of the maximal evoked response. The half-maximal responses ranged from 0.3 to $1.3 \mathrm{mV}$ in the DLS and 0.2 to 1.2 in the $\mathrm{nAc}$, and were evoked with stimuli of $0.02-0.05 \mathrm{~mA}$ in intensity. For recordings in the DLS the stimulation electrode was placed at the border of the subcortical white matter and the striatum (Figure 1A). For recordings in the nAc core, the stimulation electrode was placed locally close to the anterior commissure dorsal to the recording electrode (Figure 1A). In a subset of recordings PSs were evoked in the dorsomedial striatum. For these recordings the stimulation electrode was placed inside the striatum, as previously described by Yin et al. (2007). After monitoring a stable baseline for $10 \mathrm{~min}$ slices were treated with $\mathrm{GABA}_{\mathrm{A}}$ receptor inhibitors (picrotoxin, $100 \mu \mathrm{M}$; bicuculline, 2, $20 \mu \mathrm{M}$ ), glycine receptor inhibitors [strychnine, $0.1,1 \mu \mathrm{M}$, phenylbenzene $\omega$-phosphono- $\alpha$-amino acid (PMBA), $50 \mu \mathrm{M}$ ], or the nicotinic acetylcholine receptor antagonist mecamylamine $(10 \mu \mathrm{M}$; Sigma Aldrich, St Louis, MO, USA). Bicuculline was dissolved to $20 \mathrm{mM}$ in DMSO and diluted to 2 or $20 \mu \mathrm{M}$ in aCSF. All other drugs were dissolved in aCSF. Signals were amplified by a custom made amplifier, filtered at $3 \mathrm{kHz}$, digitized at $8 \mathrm{kHz}$ (12-bit Analog-Digital converter with a maximum range of $10 \mathrm{~V}$ ) and transferred to a PC for further analysis.

\section{MICRODIALYSIS}

Male Wistar rats (Taconic, Ejby, Denmark) weighing 270-350 g were housed four to a cage under controlled environmental conditions (constant room temperature of $22^{\circ} \mathrm{C}$, humidity of $65 \%$, and regular light-dark conditions with lights on at 07:00 AM and off at 07:00 PM). Animals had free access to tap water and standard rat feed (Lantmännen, Kimstad, Sweden) and were allowed to adapt to the novel environment for at least 1 week before any procedures were initiated. Only drug-naïve animals were used and all experiments were performed during the light-phase of the cycle. The experimental protocols were approved by the Ethics Committee for Animal Experiments, Gothenburg, Sweden.

\section{SURGERY AND EXPERIMENTAL PROCEDURE}

Surgery was performed as previously described (Lidö et al., 2009). In brief, rats were anesthetized with isoflurane, mounted onto a stereotaxic instrument (David Kopf Instruments, Tujunga, CA, USA), and put on a heating pad to prevent hypothermia during the surgery. Three holes were drilled for the placement of anchoring screws and an I-shaped dialysis probe (custom made in the laboratory). The dialysis probes was lowered monolaterally into either the DLS $(\mathrm{A} / \mathrm{P}+1.2, \mathrm{M} / \mathrm{L}-3.4$ relative to bregma, $\mathrm{D} / \mathrm{V}-5.0$ relative to the dura), or the $\mathrm{nAc}(\mathrm{A} / \mathrm{P},+1.85 ; \mathrm{M} / \mathrm{L},-1.4 \mathrm{~mm}$ relative to bregma; and $\mathrm{D} / \mathrm{V},-7.8 \mathrm{~mm}$ relative to dura), and placed in the core-shell borderline region. The probe and the anchoring screws were fixed to the scull with Harvard cement (DAB Dental $\mathrm{AB}$, Stockholm, Sweden), and the rats were allowed to recover for 2 days before the dialysis experiments were initiated. On the experimental day, the sealed inlet and outlet of the probes were cut open and perfused with Ringer's solution, consisting of (in $\mathrm{mM}) 140 \mathrm{NaCl}, 1.2 \mathrm{CaCl}_{2}, 3.0 \mathrm{KCl}$, and $1.0 \mathrm{MgCl}_{2}$, at a rate of $2 \mu \mathrm{l} / \mathrm{min}$ for at least $1 \mathrm{~h}$ to obtain a balanced fluid exchange before baseline sampling began. After a stable baseline had been confirmed drug administration was initiated. Separate groups of 

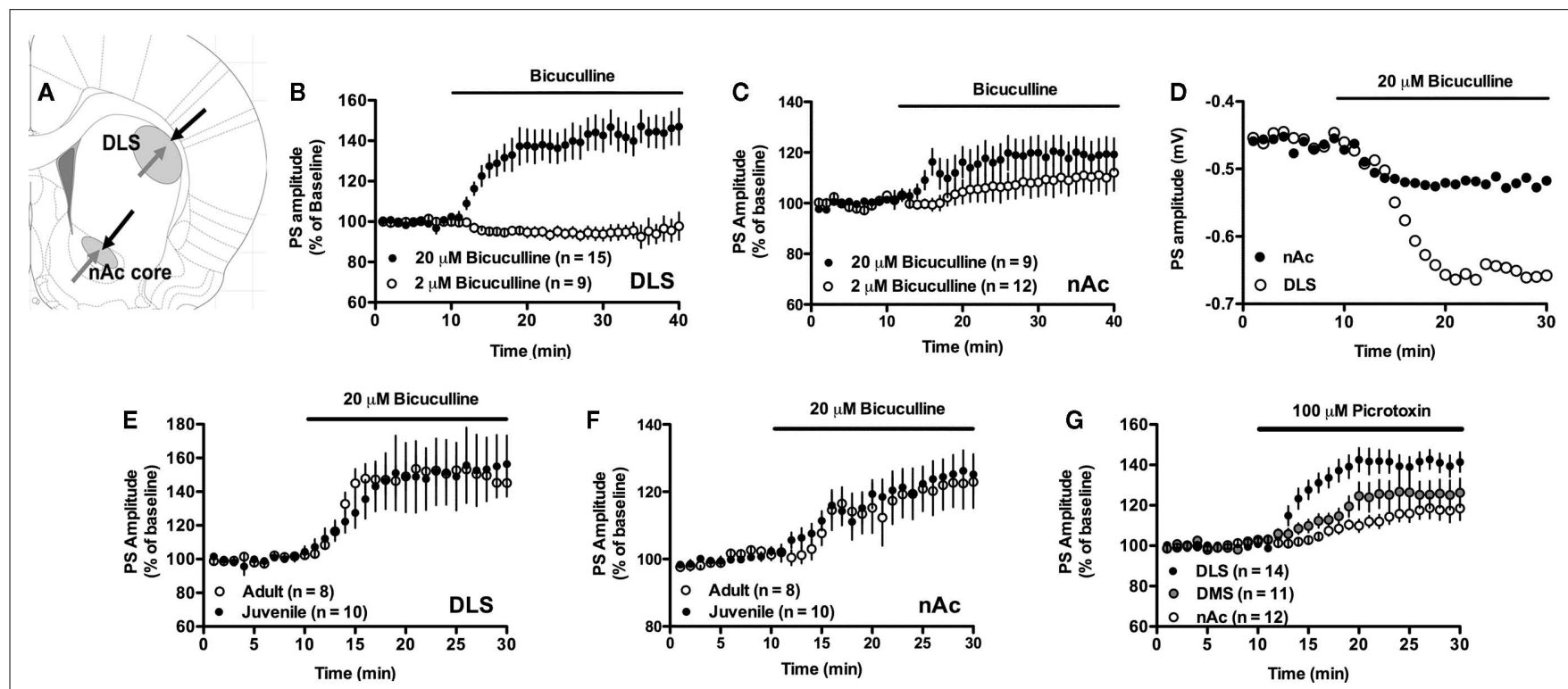

FIGURE 1 | Excitatory input to the striatum is inhibited by GABAergic neurotransmission. (A) Schematic picture showing the location of stimulating electrodes (black) and recording electrodes (gray) in the dorsolateral striatum (DLS) and in the $\mathrm{nAc}$ core. (B,C) Treatment with $20 \mu \mathrm{M}$ but not $2 \mu \mathrm{M}$, of the GABA $A_{A}$ receptor antagonist bicuculline enhanced PS amplitude in both the DLS and the nAc. (D) Example figure showing absolute
PS amplitude over time in the DLS and nAc during bicuculline-treatment. (E,F) The increase in PS amplitude induced by $20 \mu \mathrm{M}$ bicuculline sustained in slices from adult Wistar rats. (G) Treatment with the $\mathrm{GABA}_{A}$ receptor blocker picrotoxin $(100 \mu \mathrm{M})$ increased PS amplitude in the DLS, the dorsomedial striatum (DMS), and in the nAc. Data show mean PS amplitudes compared to baseline with SEM. rats received either bicuculline $(50,100 \mu \mathrm{M})$, or strychnine $(20$, $200 \mu \mathrm{M})$. In a subset of experiments one additional probe was implanted into the anterior VTA $(\mathrm{A} / \mathrm{P}-5.2, \mathrm{M} / \mathrm{L}-0.7$ relative to bregma, $\mathrm{D} / \mathrm{V}-8.4$ relative to the dura). The $\mathrm{nAChR}$ antagonist mecamylamine $(100 \mu \mathrm{M})$ was administered to the VTA in parallel to bicuculline $(50 \mu \mathrm{M})$ perfusion in the nAc. By the end of the experiment (-)-nicotine hydrogen tartrate salt dissolved in $0.9 \%$ $\mathrm{NaCl}$ and neutralized with $\mathrm{NaHCO}_{3}$, was administered subcutaneously in a volume of $2.0 \mathrm{ml} / \mathrm{kg}$. The nicotine dose is expressed in result section as free base. Dialysate samples $(40 \mu \mathrm{l})$ were collected every $20 \mathrm{~min}$. Animals were sacrificed directly after the experiment and brains were placed in accustain (Sigma diagnostics, USA) for 3-7 days before probe placements were verified using a vibroslicer (Campden Instruments Ltd., Lafayette, IN, USA; Figure 5). Animals with inaccurate probe placements were excluded, as were animals showing hemorrhaging due to probe insertion.

\section{BIOCHEMICAL ASSAYS}

Microdialysate dopamine content was separated and quantified using high performance liquid chromatography with electrochemical detection (HPLC-ED), as previously described in detail by Lidö et al. (2009). In brief, a stainless steel ion exchange column of $2 \mathrm{~mm} \times 150 \mathrm{~mm}$, operated at $32^{\circ} \mathrm{C}$, and packed with Nucleosil ( $5 \mu \mathrm{M}$; SA 100A Phenomenex Scandinavia, Västra Frölunda, Sweden) was used. The mobile phase (flow rate $0.3 \mathrm{ml} / \mathrm{min}$ ) consisted of (in mM) 58 Citric acid, $135 \mathrm{NaOH}, 0.107 \mathrm{Na}_{2}$-EDTA, as well as $20 \% \mathrm{MeOH}$. The electrochemical detector (Decade, Kovalent AB, Sweden) operated at $400 \mathrm{mV}$ vs. the cell (Hy-REF). An external standard containing $3.25 \mathrm{fmol} / \mu \mathrm{l}$ of dopamine was used to identify the dopamine peak, as well as quantify dopamine concentrations in the dialysates. All samples were analyzed on-line. The average of the last two stable baseline values was set to $100 \%$ for each animal.

\section{DATA ANALYSIS}

All graphs were assembled in GraphPad Prism (GraphPad Software, Inc., San Diego, CA, USA), and Photoshop.

Field potential recordings; Data was analyzed with Clampex 10.1 (Molecular Devices, Foster City, CA, USA). Data is presented in text as mean PS amplitude compared to baseline with $95 \%$ confidence interval (CI) at $t=25-30$ min unless anything else is clearly stated. PSs were evoked every $20 \mathrm{~s}$ and recorded amplitudes were combined to give a mean value for each min. Time course figures show mean PS amplitude compared to baseline for all recordings, with SEM. Example traces are mean values calculated at baseline and following 15-20 min of drug treatment for one representative recording. Two-tailed paired $t$-test was used for statistical analysis unless anything else is stated.

Microdialysis; Two-way ANOVA with Bonferroni post-test to compare replicate means by row was used for data analysis.

\section{RESULTS}

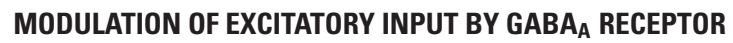 INHIBITORS}

Treatment with a low concentration of the competitive $\mathrm{GABA}_{\mathrm{A}}$ receptor antagonist bicuculline $(2 \mu \mathrm{M})$ did not significantly modulate PS amplitude in the DLS (PS amplitude $=95 \pm 5 \%$ of baseline, $t=1.92, n=10, p>0.05$ ), or nAc core (PS amplitude $=111 \pm 15 \%$ of baseline, $t=1.50, n=13, p>0.05$; Figures 1B,C), while a higher concentration $(20 \mu \mathrm{M})$ enhanced 
PS amplitude in both DLS and nAc (Figures 1B,C). The relative increase was significantly higher in the DLS as compared to the nAc core (DLS: $141 \pm 16 \%$ of drug-free baseline; nAc: $119 \pm 12 \%$ of drug-free baseline; DLS vs. nAc, unpaired $t$-test, $t=2.08, \mathrm{df}=21, p<0.05)$. The increase in PS amplitude induced by $20 \mu \mathrm{M}$ bicuculline was sustained in slices from adult Wistar rats (DLS: $149 \pm 16 \%$ of drug-free baseline; nAc: $122 \pm 14 \%$ of drug-free baseline; DLS vs. nAc, unpaired $t$-test, $t=2.55, \mathrm{df}=24$, $p<0.05$; Figures 1E,F).

Treatment with the non-competitive $\mathrm{GABA}_{\mathrm{A}}$ receptor inhibitor picrotoxin $(100 \mu \mathrm{M})$ also enhanced PS amplitude in the DLS and in the nAc core (DLS: PS amplitude $=141 \pm 9.3 \%$ of drug-free baseline, $t=8.37, n=15, p<0.001$; nAc: PS amplitude $=118 \pm 9.4 \%$ of drug-free baseline, $t=3.51, n=11$, $p<0.01$; Figure 1G). Picrotoxin also facilitated evoked PS in the dorsomedial striatum (PS amplitude $=126 \pm 13 \%$ of baseline, $t=3.63, n=11, p<0.01$; Figure 1G).

\section{GLYCINE RECEPTORS IN THE STRIATUM ARE TONICALLY ACTIVATED}

Treatment with the competitive glycine receptor antagonist strychnine $(0.1 \mu \mathrm{M})$ induced a small, but significant, increase in PS amplitude in the nAc core $(113 \pm 8.7 \%$ of baseline, $t=2.85, n=9$, $p<0.05)$. A similar trend, although not significant, was indicated in the DLS ( $109 \pm 14 \%$ of baseline, $t=1.25, n=9, p>0.05$; Figure 2A). Administration of a higher concentration $(1 \mu \mathrm{M})$ significantly enhanced PS amplitude in both the DLS and the nAc core, suggesting that glycine receptors exhibit a tonic inhibition in both subregions (DLS: $114 \pm 9.5 \%$ of drug-free baseline, $t=2.81, n=10, p<0.05$; nAc: PS amplitude $=127 \pm 11 \%$ of drug-free baseline, $t=4.69, n=8, p<0.001$; Figure 2B). The increase in PS amplitude in the nAc remained over time and was not reduced following $1 \mathrm{~h}$ of strychnine-treatment (PS amplitude at $t=60-65 \mathrm{~min}=139 \pm 21 \%$ of drug-free baseline, $t=3.71$, $n=6, p<0.05$; Figure 2C). PS amplitude was not enhanced further by a higher concentration of strychnine $(10 \mu \mathrm{M}$; DLS: $114 \pm 9.2 \%$ of drug-free baseline, $t=3.01, n=10, p<0.05$; nAc: PS amplitude $=126 \pm 11 \%$ of drug-free baseline, $t=4.66, n=11$, $p<0.001$; data not shown). Increased excitatory input following strychnine administration was also confirmed in slices from adult Wistar rats (DLS: $111 \pm 9.2 \%$ of drug-free baseline, $t=2.40$, $n=8, p<0.05$; nAc: $125 \pm 9.8 \%$ of drug-free baseline, $t=4.75$, $n=9, p<0.01$; Figures 2D,E). PS amplitude was also enhanced by the non-competitive glycine receptor antagonist PMBA $(50 \mu \mathrm{M}$; DLS: $130 \pm 14 \%$ of drug-free baseline, $t=4.1, n=12, p<0.01$; nAc: $119 \pm 12 \%$ of drug-fee baseline, $t=3.16, n=12, p<0.01$; Figure 2F).

\section{DEACTIVATION OF GLYCINE RECEPTORS INCREASE THE EXCITATORY INPUT TO THE STRIATUM THROUGH MODULATION OF CHOLINERGIC AND GABAergic NEUROTRANSMISSION}

Inhibition of nicotinic acetylcholine receptors by the non-selective and non-competitive antagonist mecamylamine for at least $20 \mathrm{~min}$ before administration of $1 \mu \mathrm{M}$ strychnine significantly depressed the increase in PS amplitude induced by strychnine alone (nAc: $112 \pm 2.8 \%$ of mecamylamine-treated baseline, strychnine vs. strychnine + mecamylamine-treated slices, unpaired $t$-test,
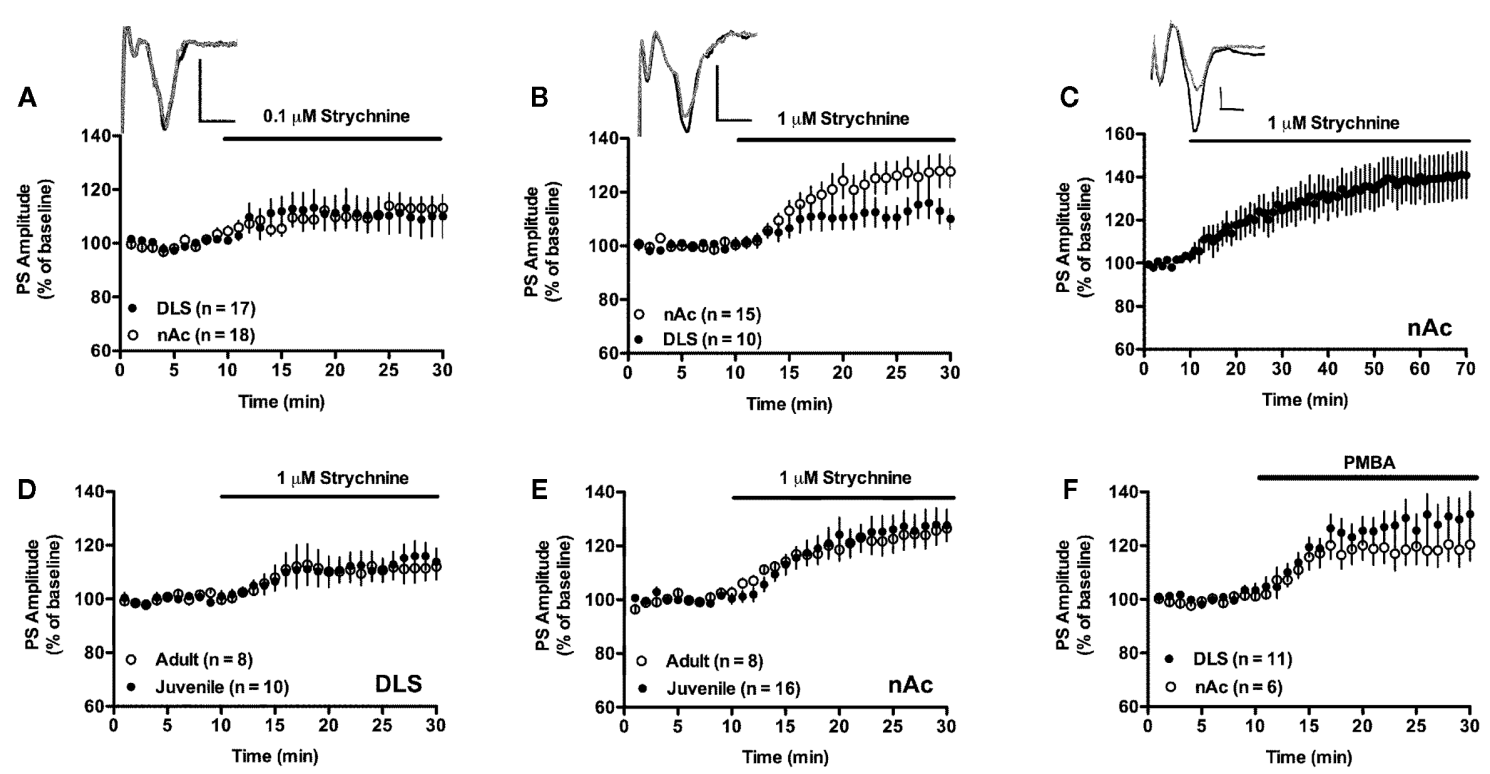

FIGURE 2 | Glycine receptors are tonically activated and depress excitatory input. (A) Inhibition of glycine receptors with $0.1 \mu \mathrm{M}$ strychnine induced a small increase in PS amplitude in the $\mathrm{nAc}$, and there was a trend for a similar effect in the DLS. Example traces show evoked PSs at baseline (gray), and after 15-20 min exposure to $0.1 \mu \mathrm{M}$ strychnine (black) in the DLS. (B) Treatment with a higher concentration of strychnine enhanced PS amplitude in both the DLS and in the nAc. Example traces show evoked PSs at baseline (gray), and after
15-20 min exposure to $1 \mu \mathrm{M}$ strychnine (black) in the DLS. (C) The enhancing effect displayed by strychnine was not depressed over time. Example traces show evoked PSs at baseline (gray), and after 50-55 min exposure to $1 \mu \mathrm{M}$ strychnine (black) in the nAc. (D,E) Strychnine enhanced PS amplitude to a similar extent in slices from adult Wistar rats. (F) PS amplitudes in the DLS and in the $\mathrm{nAc}$ were also enhanced by the glycine receptor antagonist PMBA $(50 \mu \mathrm{M})$. Data show mean PS amplitudes compared to baseline with SEM. Calibration: $0.2 \mathrm{mV}, 2 \mathrm{~ms}$. 


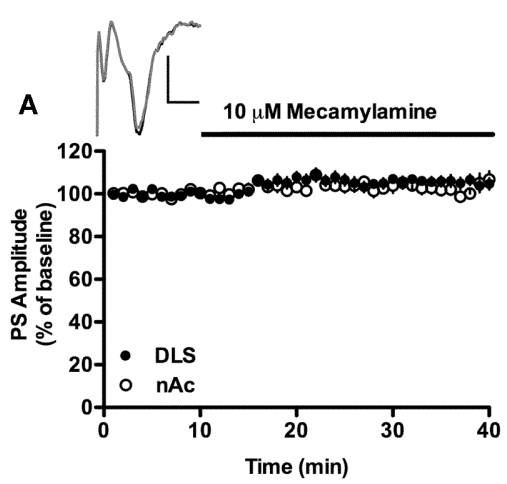

FIGURE 3 | Strychnine-induced enhancement of PS amplitude involves nicotinic but not muscarinic acetylcholine receptors. (A) Treatment with the nicotinic acetylcholine receptor inhibitor mecamylamine $(10 \mu \mathrm{M})$ did not enhance PS amplitude in the DLS or in the nAc core. Example traces show evoked population spikes in the DLS at baseline (gray) and after 15-20 min of mecamylamine-treatment (black). (B) The strychnine-induced enhancement of

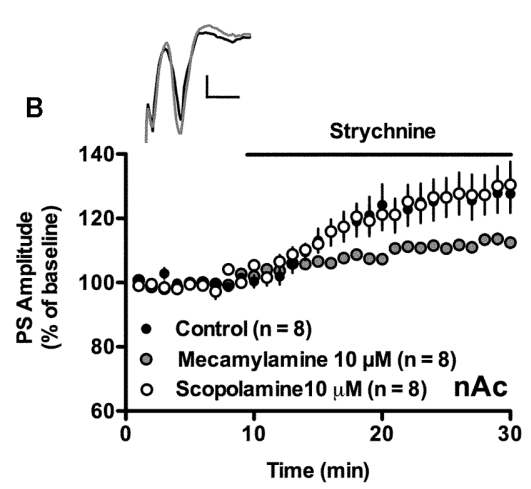

PS amplitudes recorded in the nAc core remained in slices treated with the muscarinic acetylcholine receptor antagonist scopolamine $(10 \mu \mathrm{M})$, but was significantly depressed in mecamylamine-treated slices. Example traces show evoked population spikes at baseline (gray) and after 15-20 min of strychnine administration in a scopolamine-treated slice (black). Data show mean PS amplitudes compared to baseline with SEM. Calibration: $0.2 \mathrm{mV}, 2 \mathrm{~ms}$. $t=2.53, \mathrm{df}=30, p<0.05$; Figure 3B). Treatment with the non-selective muscarinic antagonist scopolamine $(10 \mu \mathrm{M})$ did not modulate the strychnine-induced increase in PS amplitude $(128 \pm 12 \%$ of scopolamine-treated baseline, $t=4.55, n=8$, $p<0.01$; Figure 3B). Baseline PS amplitude was not significantly modulated by mecamylamine (DLS: $105 \pm 4.8 \%, t=2.20$, $n=11$; nAc: $103 \pm 4.12 \%, t=1.62, n=13, p>0.05$; Figure 3A) or scopolamine (PS amplitude $=102 \pm 6.8 \%$ of drug-free baseline, $t=0.69, n=7, p>0.05$; data not shown).

Pre-treatment with picrotoxin $(100 \mu \mathrm{M})$ inhibited the strychnine-mediated increase in PS amplitude in both the DLS $(101 \pm 7.9 \%$ of picrotoxin-treated baseline, strychnine vs. strychnine + picrotoxin, $\mathrm{df}=21, t=2.11, p<0.05$; Figure $4 \mathrm{~A})$, and in the nAc core (PS amplitude $=108 \pm 7.1 \%$ of picrotoxin-treated baseline, strychnine vs. strychnine + picrotoxin, unpaired $t$-test, $t=2.77, \mathrm{df}=14, p<0.01$; Figure $4 \mathrm{~B})$. This result was further supported by the finding that bicuculline $(20 \mu \mathrm{M})$ significantly depressed the strychnine-induced increase in PS amplitude in the $\mathrm{nAc}(109 \pm 3.7 \%$ of bicuculline-treated baseline, strychnine vs. strychnine + bicuculline, unpaired $t$-test, $t=3.0, \mathrm{df}=14$, $p<0.01$; Figure 4B), and the PMBA-induced enhancement of PS amplitude in the DLS $(103 \pm 7.2 \%$ of bicuculline-treated baseline, PMBA vs. PMBA + bicuculline, unpaired $t$-test, $t=3.12, \mathrm{df}=21$, $p<0.01$; Figure 4C). The strychnine-induced enhancement of PS amplitude was also inhibited by a lower concentration of bicuculline $(2 \mu \mathrm{M})$, which by itself had no influence on PS amplitude (see Figure 1; DLS: $101 \pm 3.2 \%$ of bicuculline-treated baseline, $t=0.30, n=8, p>0.05$; nAc: $105 \pm 3.2 \%$ of bicuculline-treated baseline, strychnine vs. bicuculline + strychnine, unpaired $t$-test, $t=3.12$, df $=17, p<0.01$; Figure 4D).

\section{MICRODIALYSIS}

Local treatment with bicuculline $(50 \mu \mathrm{M})$ in the dorsal striatum did not significantly modulate dopamine release at any specific time point (Time $\times$ drug interaction: $F=1.64, p>0.05$; Drug: $F=3.10, p>0.05$; Figure 6A). A higher concentration of bicuculline $(100 \mu \mathrm{M})$ in the same brain region enhanced the microdialysate concentration of dopamine (Time $\times$ drug interaction: $F=19.20, p<0.001$; Drug: $F=32.38, p<0.001$; Figure 6A). However, after $1 \mathrm{~h}$ of drug treatment the animals started to twitch with their heads toward the side to which bicuculline was administered, and the experiments were instantly terminated.

In the $\mathrm{nAc}$, administration of $50 \mu \mathrm{M}$ bicuculline was sufficient to induce a robust increase in dopamine concentration (Time $\times$ drug interaction: $F=16.87, p<0.001$; Drug: $F=18.38$, $p<0.01$; Figure 6B). Due to the adverse effects seen after administration of $100 \mu \mathrm{M}$ bicuculline in the DLS, this concentration was not administered in the nAc.

In a subset of experiments the nicotinic acetylcholine receptor antagonist mecamylamine $(100 \mu \mathrm{M})$ was administered in the VTA for $40 \mathrm{~min}$ before and continuously during bicuculline perfusion. By the end of these experiments animals received a subcutaneous injection of nicotine $(0.4 \mathrm{mg} / \mathrm{kg})$. Mecamylamine did not prevent the bicuculline-induced increase in dopamine output, but blocked the nicotine-induced elevation of dopamine (Time $\times$ drug interaction: $F<1.0, p>0.05$; Drug: $F<1.0, p>0.05$; Figure 6C).

Treatment with the glycine receptor antagonist strychnine $(20 \mu \mathrm{M})$ did not significantly modulate the microdialysate concentration of dopamine in the DLS (Time $\times$ drug interaction: $F \leq 1.0, p>0.05 ; p>0.05$; Drug: $F \leq 1.0, p>0.05$ ), or the nAc (Time $\times$ drug interaction: $F=1.616, p>0.05 ; p>0.05$; Drug: $F \leq 1.0, p>0.05$; Figures 6D,E). However, administration of a higher concentration of strychnine $(200 \mu \mathrm{M})$, significantly depressed the microdialysate concentration of dopamine in both the DLS (Time $\times$ drug interaction: $F=49.56, p<0.001$; $p>0.05$; Drug: $F=44.14, p<0.001$; Figure 6F), and in the $\mathrm{nAc}$ (Time $\times$ drug interaction: $F=18.42, p<0.05$; Time: $F=41.91$, $p<0.001$; Drug: $F=32.05, p<0.001$; Figure 6F).

\section{DISCUSSION}

GABAergic MODULATION OF EXCITATORY INPUT AND EXTRACELLULAR DOPAMINE LEVELS

Synaptic transmission in the striatum is inhibited by two distinct GABAergic circuits; The feedforward circuit consisting of 


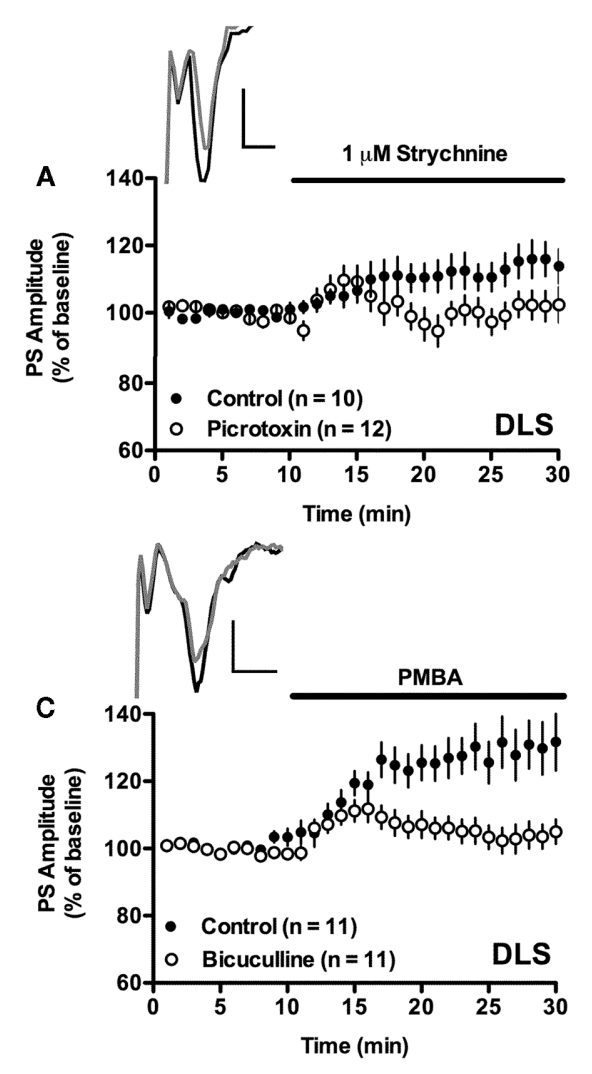

FIGURE 4 | Tonically activated glycine receptors depress excitatory input to the striatum via $\mathbf{G A B A}_{\mathbf{A}}$ receptors. $(\mathbf{A}, \mathbf{B})$ The strychnineinduced enhancement of PS amplitude was significantly depressed in slices treated with the $\mathrm{GABA}_{\mathrm{A}}$ receptor blockers picrotoxin $(100 \mu \mathrm{M})$ or bicuculline $(20 \mu \mathrm{M})$. Example traces show evoked population spikes at baseline (gray) and after 15-20 min of strychnine-treatment (black) in a control slice (A) and in a bicuculline-treated slice (B). (C) The increase in PS amplitude induced by the glycine receptor antagonist PMBA $(50 \mu \mathrm{M})$ was also
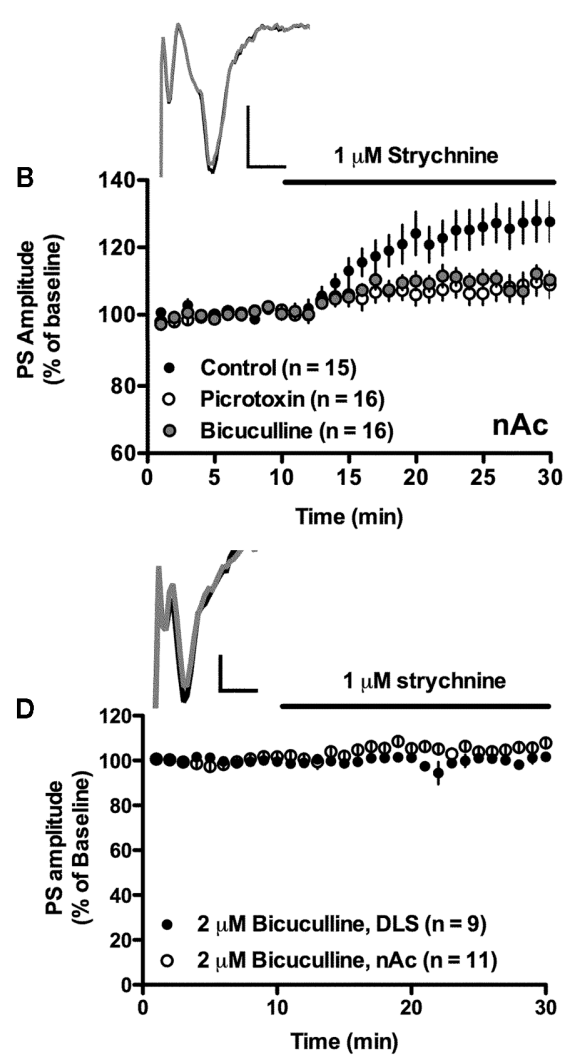

prevented in slices treated with bicuculline (20 $\mu$ M). Example traces show evoked population spikes at baseline (black) and after 15-20 min of PMBA-treatment (gray). (D) Slices treated with a lower concentration of bicuculline $(2 \mu \mathrm{M})$ also inhibited strychnine-induced enhancement of PS amplitudes. Example traces show evoked population spikes in the nAc at baseline (black) and after 15-20 min of strychnine perfusion in a bicuculline-treated slice (gray). Data show mean PS amplitudes compared to baseline with SEM. Calibration: $0.2 \mathrm{mV}, 2 \mathrm{~ms}$.
GABAergic interneurons and the feedback circuit comprising of MSNs (Tepper et al., 2004). Even though GABAergic interneurons are outnumbered by MSNs, feedforward inhibition appears to be more powerful with respect to the total number of synapses, the synaptic strength, and the net effect on the postsynaptic activity of the MSN (Tepper et al., 2008). Furthermore, intrastriatal stimulation has previously been shown to preferentially activate inhibitory synapses provided by interneurons (Tecuapetla et al., 2005). Treatment with a high concentration of picrotoxin $(100 \mu \mathrm{M})$ or bicuculline $(20 \mu \mathrm{M})$ enhanced PS amplitude by $40 \%$ in the DLS showing that, even though the majority of synapses are glutamatergic, GABAergic neurotransmission exerts a strong influence on the excitatory input to the striatum (Wilson, 2007). Inhibition of $\mathrm{GABA}_{\mathrm{A}}$ receptors also enhanced $\mathrm{PS}$ amplitude in the $\mathrm{nAc}$, but to a lesser extent, which might be related to differences in GABAergic tone, receptor localization, or to the orientation of dendritic arbors. Brain region specific localization of $\mathrm{GABA}_{\mathrm{A}}$ receptors has previously been reported in other structures of the basal ganglia. In the globus pallidus, $\mathrm{GABA}_{\mathrm{A}}$ receptors are exclusively postsynaptic (Charara et al., 2005), while, in the $\mathrm{nAc}, \mathrm{GABA}_{\mathrm{A}}$ receptors containing the alpha 1 subunit are localized on presynaptic terminals (Churchill et al., 1991). Furthermore, in the VTA, $\mathrm{GABA}_{\mathrm{A}}$ receptors appear to be localized on both dopaminergic neurons and on GABAergic interneurons, resulting in both direct inhibition and indirect disinhibition of dopamine release (Xi and Stein, 1998).

The striatal nucleus is innervated by dopaminergic fibers that arise from the substantia nigra and the VTA (Voorn et al., 2004; Ikemoto, 2007). Dopamine has previously been shown to play a selective role in the presynaptic modulation of recurrent axon collaterals that interconnect spiny neurons (Guzmán et al., 2003), but dopaminergic firing in all parts of the striatum is also by itself influenced by GABAergic neurotransmission (Santiago and Westerink, 1992; Westerink et al., 1998; Tepper and Lee, 2007). The data presented here shows that administration of bicuculline enhances the microdialysate concentration of dopamine in both the $\mathrm{nAc}$ and in the dorsal striatum. A lower concentration of bicuculline $(50 \mu \mathrm{M})$ only elevated the microdialysate concentration of dopamine in the nAc. The GABAergic influence on dopaminergic output thus appears stronger in the nAc than in the DLS and is 

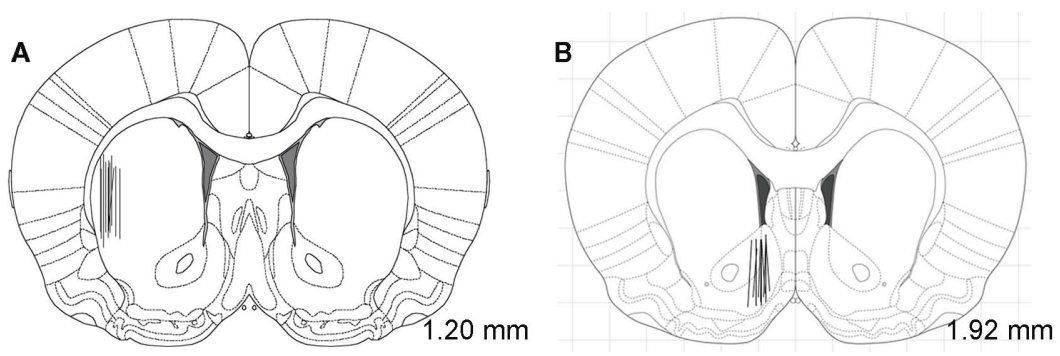

FIGURE $\mathbf{5}$ | Location of the microdialysis probes in the DLS and $\mathbf{n A c}$. The black lines indicate the track of individual microdialysis probes in the DLS (A) and the $\mathrm{nAc}(\mathbf{B})$. Distance from bregma (in $\mathrm{mm}$ ) is shown to the right in each figure.
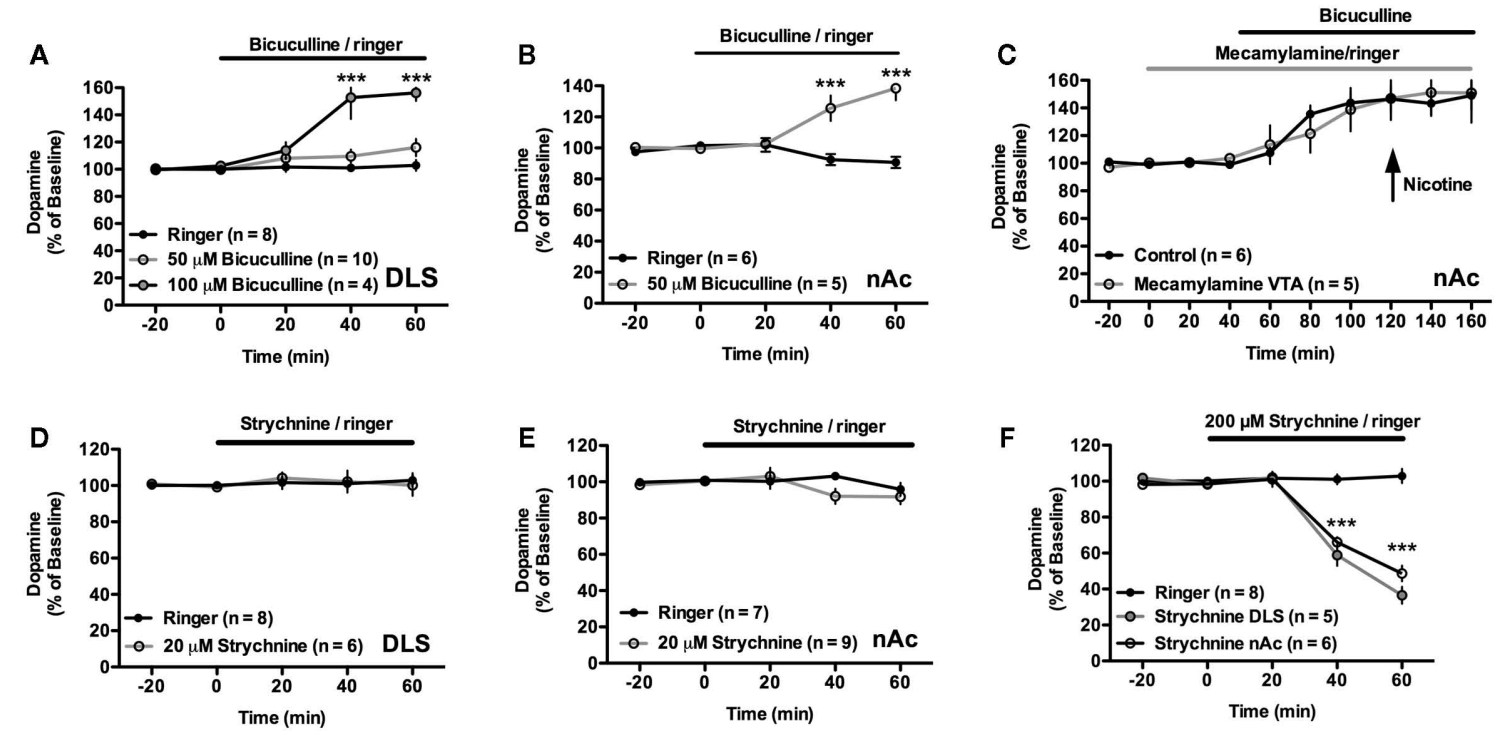

FIGURE 6 |The microdialysate concentration of dopamine is regulated by $\mathrm{GABA}_{\mathrm{A}}$ and glycine receptors. (A) The microdialysate concentration of dopamine was significantly enhanced by $100 \mu \mathrm{M}$ but not by $50 \mu \mathrm{M}$ bicuculline in the DLS (B) Bicuculline $(50 \mu \mathrm{M})$ applied by reversed microdialysis in the $\mathrm{nAc}$ enhanced the extracellular level of dopamine. (C) The increase in dopamine output induced by bicuculline administration in the nAc was not significantly modulated by mecamylamine co-perfused in the VTA. (D,E) The microdialysate concentration of dopamine was not depressed by $20 \mu \mathrm{M}$ strychnine in either brain region. (F) A higher concentration of strychnine $(200 \mu \mathrm{M})$ significantly depressed dopamine levels in both the DLS and in the $\mathrm{nAc}$. probably largely unrelated to the GABAergic influence on excitatory input, as measured in the present set-up, which was stronger in the DLS than in the nAc. This finding further points toward a subregional distribution of $\mathrm{GABA}_{\mathrm{A}}$ receptors, but it should be noted that $\mathrm{GABA}_{\mathrm{A}}$ receptor-mediated release of dopamine might be further complicated by indirect and direct interactions in the VTA and substantia nigra (Westerink et al., 1996).

Increased dopamine release in the $\mathrm{nAc}$, as measured by microdialysis, may after accumbal drug administration involve a nAcVTA-nAc neuronal circuitry employing nicotinic receptor activation in the VTA and subsequent activation of dopamine neurons (Blomqvist et al., 1993, 1997; Söderpalm et al., 2009). In order to evaluate if such a neurocircuitry was involved in bicucullinemediated dopamine release we administered mecamylamine in the VTA in parallel to bicuculline perfusion in the nAc. The bicuculline-induced increase in microdialysate concentration of dopamine was not blocked by mecamylamine, suggesting that $\mathrm{GABA}_{\mathrm{A}}$ receptor inhibition modulates dopamine release either locally within the nAc or via a neurocircuitry different from the nAc-VTA-nAc previously described. Importantly, the dopamine elevating property of nicotine was prevented by mecamylamine showing that nicotinic receptors in the VTA were indeed blocked (Grenhoff et al., 1986).

In favor of the dopamine output being influenced by GABAergic neurotransmission locally in the $\mathrm{nAc}$, e.g., via interference with presynaptic $\mathrm{GABA}_{\mathrm{A}}$ receptors on dopaminergic terminals, may be the fact that such receptors previously have been implicated in modulation of dopamine release (Aono et al., 2008). However, another study performed in the striatum has suggested that $\mathrm{GABA}_{\mathrm{A}}$ receptor antagonists primarily modulate dopamine release postsynaptically via the striatonigral feedback loop (Smolders et al., 1995). It is thus possible that the $\mathrm{GABA}_{\mathrm{A}}$ 
receptor is heterogeneously distributed within the basal ganglia, and that these differences in localization enables it to contribute differentially to various patterns of activity.

\section{GLYCINERGIC MODULATION OF EXCITATORY INPUT AND EXTRACELLULAR DOPAMINE LEVELS}

Even though the expression of glycine receptors in the striatum is relatively low (Malosio et al., 1991), they appear to be involved in regulating basal dopamine levels and neurotransmission (Yadid et al., 1993; Molander and Söderpalm, 2005b). Treatment with strychnine enhanced PS amplitude in both the DLS and nAc suggesting that glycine receptors are tonically activated and exert a net inhibitory control of excitatory input. This finding was also confirmed in slices treated with PMBA, which has been reported not to interact with $\alpha 7$ nicotinic acetylcholine, NMDA, or $\mathrm{GABA}_{\mathrm{A}}$ receptors when used at concentrations below $100 \mu \mathrm{M}$ (Saitoh et al., 1994; Renna et al., 2007). The glycine receptor can be activated by glycine, taurine, and $\beta$-alanine, and microdialysate sampling from the nAc has shown that all three agonists are present at measurable levels during baseline conditions (Lidö et al., 2009; Adermark et al., 2011). This, in connection with the present data, indicates that the glycine receptor is most likely endogenously activated during baseline conditions. Furthermore, there was no significant difference between data retrieved from juvenile rats and adult brain slices, showing that there is no age related difference in glycinergic tonicity when comparing slices from these two ages.

The immunoreactivity for glycine receptors in the striatum colocalizes primarily with choline acetyl transferase (Darstein et al., 1997), and activation of glycine receptors enhance strychninesensitive acetylcholine release in vitro (Hernandes et al., 2007). Since striatal cholinergic interneurons drive excitation of surrounding GABAergic neurons (de Rover et al., 2002), activation of cholinergic interneurons could be converted into widespread recurrent inhibition via nicotinic excitation of GABAergic neurons (Sullivan et al., 2008). Involvement of both nicotinic and $\mathrm{GABA}_{A}$ receptors in strychnine-mediated enhancement of excitatory input was also supported by our data showing that the increase in PS amplitude was inhibited by mecamylamine, picrotoxin, and bicuculline. This blockade was not connected to a ceiling effect caused by disinhibition since a lower concentration of bicuculline, which did not influence excitatory input, also blocked the strychnineinduced enhancement of PS amplitude. However, the increase in PS amplitude was only partially depressed by mecamylamine, and it is thus possible that glycine receptors located elsewhere could contribute to the net inhibition of excitatory input to the striatum. For instance, glycine receptors could be expressed by

\section{REFERENCES}

Adermark, L., Clarke, R. B., Olsson, T., Hansson, E., Söderpalm, B., and Ericson, M. (2011). Implications for glycine receptors and astrocytes in ethanol-induced elevation of dopamine levels in the nucleus accumbens. Addict. Biol. 16, 43-54.

Adermark, L., and Lovinger, D. M. (2009). Frequency-dependent inversion of net striatal output by endocannabinoid-dependent plasticity at different synaptic inputs. J. Neurosci. 29, 1375-1380.

Aono, Y., Saigusa, T., Mizoguchi, N., Iwakami, T., Takada, K., Gionhaku, N., Oi, Y., Ueda, K., Koshikawa, N., and Cools, A. R. (2008). Role of GABAA receptors in the endomorphin-1-, but not endomorphin-2-, induced dopamine efflux in the nucleus accumbens of freely moving rats. Eur. J. Pharmacol. 580, 87-94.

parvalbumin expressing GABAergic interneurons, and thus control striatal activity by modulating feedforward inhibition (Tepper et al., 2004; Waldvogel et al., 2007). Furthermore, even though glycine receptors have not been confirmed to be expressed by MSNs, the glycine receptor agonist taurine has been shown to induce strychnine-sensitive chloride-mediated currents in these neurons (Sergeeva and Haas, 2001). Thus, glycine receptors might also be expressed by GABAergic neurons, and directly or indirectly modulate striatal neurotransmission.

We have previously shown that activation of accumbal glycine receptors with glycine, taurine, or $\beta$-alanine increases the microdialysate concentration of dopamine in a strychnine-sensitive manner (Molander and Söderpalm, 2005b; Ericson et al., 2006, 2010, 2011). Furthermore, previous data (Molander and Söderpalm, 2005b) and the data presented here show that strychnine depresses extracellular dopamine levels in both the nAc and in the DLS. Interestingly, accumbal dopamine is enhanced by glycine in vivo but not in slice recordings where the connection between the striatum and dopaminergic cell bodies has been cut off (Molander and Söderpalm, 2005b; Hernandes et al., 2007). The dopamine-regulating impact displayed by glycine receptors in the $\mathrm{nAc}$ thus appears to involve activation of dopaminergic cell bodies in the VTA. Whether the nigrostriatal feedback loop is involved in regulating strychnine-mediated dopamine depression in the DLS remains to be determined. Drug concentration in the microdialysis experiments was increased compared to drug concentration used in the field potential recordings since previous data has shown that only a fraction of the drug administered diffuses out of the microdialysis probe, even when small molecules such as ethanol are perfused (Robinson et al., 2000).

In conclusion, the data presented here suggest that $\mathrm{GABA}_{\mathrm{A}}$ receptors and glycine receptors in the striatum regulate excitatory input to the dorsal and ventral striatum, and modulate extracellular dopamine levels in a partially subregion-specific manner.

\section{ACKNOWLEDGMENTS}

We appreciate the help provided by Helena Karlsson and Anne Fagerberg, University of Gothenburg. This work was supported by the Swedish Brain foundation, Swedish Medical Research Council Council (Diary numbers 2009-2289, 2010-3100, 2009-4477), Lindahl's foundation, Harald and Greta Jeanssons foundation, the Swedish Society of Medicine (2009-22263), Tore Nilsson foundation, Thuring's foundation, Magnus Bergvall's foundation, Vilhelm och Martina Lundgrens stiftelse, Stiftelsen Lars Hiertas minne, Åke Wibergs stiftelse, Gunnar och Märta Bergendahls minne and governmental support under the LUA/ALF agreement.

Blomqvist, O., Engel, J. A., Nissbrandt, H., and Söderpalm, B. (1993). The mesolimbic dopamineactivating properties of ethanol are antagonized by mecamylamine. Eur. J. Pharmacol. 249, 207-213.

Blomqvist, O., Ericson, M., Engel, J. A., and Söderpalm, B. (1997). Accumbal dopamine overflow after ethanol: localization of the antagonizing effect of mecamylamine. Eur. J. Pharmacol. 334, 149-156.
Bolam, J. P., Hanley, J. J., Booth, P. A., and Bevan, M. D. (2000). Synaptic organisation of the basal ganglia. J. Anat. 196, 527-542.

Charara, A., Pare, J. F., Levey, A. I., and Smith, Y. (2005). Synaptic and extrasynaptic GABA-A and GABA-B receptors in the globus pallidus: an electron microscopic immunogold analysis in monkeys. Neuroscience $131,917-933$. 
Chevalier, G., and Deniau, J. M. (1990). Disinhibition as a basic process in the expression of striatal functions. Trends Neurosci. 13, 277-280.

Churchill, L., Bourdelais, A., Austin, M., Zahm, D. S., and Kalivas, P. W. (1991). Gamma-aminobutyric acid and mu-opioid receptor localization and adaptation in the basal forebrain. Adv. Exp. Med. Biol. 295, 101-117.

Clarke, R. B., and Adermark, L. (2010). Acute ethanol treatment prevents endocannabinoid-mediated longlasting disinhibition of striatal output. Neuropharmacology 58, 799-805.

Darstein, M., Landwehrmeyer, G. B., Kling, C., Becker, C. M., and Feuerstein, T. J. (2000). Strychninesensitive glycine receptors in rat caudatoputamen are expressed by cholinergic interneurons. Neuroscience 96, 33-39.

Darstein, M., Loschmann, P. A., Knorle, R., and Feuerstein, T. J. (1997). Strychnine-sensitive glycine receptors inducing $[3 \mathrm{H}]$-acetylcholine release in rat caudatoputamen: a new site of action of ethanol? Naunyn Schmiedebergs Arch. Pharmacol. 356, 738-745.

de Rover, M., Lodder, J. C., Kits, K. S., Schoffelmeer, A. N., and Brussaard, A. B. (2002). Cholinergic modulation of nucleus accumbens medium spiny neurons. Eur. J. Neurosci. 16, 2279-2290.

Ericson, M., Chau, P., Clarke, R. B., Adermark, L., and Söderpalm, B. (2011). Rising taurine and ethanol concentrations in nucleus accumbens interact to produce dopamine release after ethanol administration. Addict. Biol. 16, 377-385.

Ericson, M., Clarke, R. B., Chau, P., Adermark, L., and Söderpalm, B. (2010). Beta-alanine elevates dopamine levels in the rat nucleus accumbens: antagonism by strychnine. Amino Acids 38, 1051-1055.

Ericson, M., Molander, A., Stomberg, R., and Söderpalm, B. (2006). Taurine elevates dopamine levels in the rat nucleus accumbens; antagonism by strychnine. Eur. J. Neurosci. 23, 3225-3229.

Grenhoff, J., Aston-Jones, G., and Svensson, T. H. (1986). Nicotinic effects on the firing pattern of midbrain dopamine neurons. Acta Physiol. Scand. 128, 351-358.

Guzmán, J. N., Hernández, A., Galarraga, E., Tapia, D., Laville, A., Vergara, R., Aceves, J., and Bargas, J. (2003). Dopaminergic modulation of axon collaterals interconnecting spiny neurons of the rat striatum. $J$. Neurosci. 23, 8931-8940.

Hernandes, M. S., de Magalhaes, L., and Troncone, L. R. (2007). Glycine stimulates the release of labeled acetylcholine but not dopamine nor glutamate from superfused rat striatal tissue. Brain Res. 1168, 32-37.

Ikemoto, S. (2007). Dopamine reward circuitry: two projection systems from the ventral midbrain to the nucleus accumbens-olfactory tubercle complex. Brain Res. Rev. 56, 27-78.

Ikemoto, S. (2010). Brain reward circuitry beyond the mesolimbic dopamine system: a neurobiological theory. Neurosci. Biobehav. Rev. 35, 129-150.

Lidö, H. H., Stomberg, R., Fagerberg, A., Ericson, M., and Söderpalm, B. (2009). The glycine reuptake inhibitor org 25935 interacts with basal and ethanol-induced dopamine release in rat nucleus accumbens. Alcohol. Clin. Exp. Res. 33, 1151-1157.

Malosio, M. L., Marqueze-Pouey, B., Kuhse, J., and Betz, H. (1991). Widespread expression of glycine receptor subunit mRNAs in the adult and developing rat brain. EMBO J. 10, 2401-2409.

Molander, A., and Söderpalm, B. (2005a). Accumbal strychninesensitive glycine receptors: an access point for ethanol to the brain reward system. Alcohol. Clin. Exp. Res. 29, 27-37.

Molander, A., and Söderpalm, B. (2005b). Glycine receptors regulate dopamine release in the rat nucleus accumbens. Alcohol. Clin. Exp. Res. 29, 17-26.

Nakano, K., Kayahara, T., Tsutsumi, T., and Ushiro, H. (2000). Neural circuits and functional organization of the striatum. J. Neurol. 247(Suppl. 5), V1-V15.

Pakhotin, P., and Bracci, E. (2007). Cholinergic interneurons control the excitatory input to the striatum. J. Neurosci. 27, 391-400.

Renna, J. M., Strang, C. E., Amthor, F. R., and Keyser, K. T. (2007). Strychnine, but not PMBA, inhibits neuronal nicotinic acetylcholine receptors expressed by rabbit retinal ganglion cells. Vis. Neurosci. 24, 503-511.

Robinson, D. L., Lara, J. A., Brunner, L. J., and Gonzales, R. A. (2000). Quantification of ethanol concentrations in the extracellular fluid of the rat brain: in vivo calibration of microdialysis probes. J. Neurochem. 75, 1685-1693.

Rushworth, M. F., Mars, R. B., and Summerfield, C. (2009). General mechanisms for making decisions? Curr. Opin. Neurobiol. 19, 75-83.

Saitoh, T., Ishida, M., Maruyama, M. and Shinozaki, H. (1994). A novel antagonist, phenylbenzene omegaphosphono-alpha-amino acid, for strychnine-sensitive glycine receptors in the rat spinal cord. $\mathrm{Br}$. J. Pharmacol. 113, 165-170.

Santiago, M., and Westerink, B. H. (1992). The role of GABA receptors in the control of nigrostriatal dopaminergic neurons: dual-probe microdialysis study in awake rats. Eur. J. Pharmacol. 219, 175-181.

Sergeeva, O. A., and Haas, H. L. (2001). Expression and function of glycine receptors in striatal cholinergic interneurons from rat and mouse. Neuroscience 104 1043-1055.

Smolders, I., De Klippel, N., Sarre, S., Ebinger, G., and Michotte, Y. (1995). Tonic GABA-ergic modulation of striatal dopamine release studied by in vivo microdialysis in the freely moving rat. Eur. J. Pharmacol. 284 83-91.

Söderpalm, B., Löf, E., and Ericson, M. (2009). Mechanistic studies of ethanol's interaction with the mesolimbic dopamine reward system. Pharmacopsychiatry 42, S87S94.

Sullivan, M. A., Chen, H., and Morikawa, H. (2008). Recurrent inhibitory network among striatal cholinergic interneurons. J. Neurosci. 28, 8682-8690.

Tecuapetla, F., Carrillo-Reid, L. Guzmán, J. N., Galarraga, E. and Bargas, J. (2005). Different inhibitory inputs onto neostriatal projection neurons as revealed by field stimulation. J. Neurophysiol. 93, 1119-1126.

Tepper, J. M., Koos, T., and Wilson, C. J. (2004). GABAergic microcircuits in the neostriatum. Trends Neurosci. 27 662-669.

Tepper, J. M., and Lee, C. R. (2007). GABAergic control of substantia nigra dopaminergic neurons. Prog. Brain Res. 160, 189-208.

Tepper, J. M., Wilson, C. J., and Koos, T. (2008). Feedforward and feedback inhibition in neostriatal GABAergic spiny neurons. Brain Res. Rev. 58, 272-281.

van Kuyck, K., Gabriels, L., Cosyns, P., Arckens, L., Sturm, V., Rasmussen, S., and Nuttin, B. (2007). Behavioural and physiological effects of electrical stimulation in the nucleus accumbens: a review. Acta Neurochir. Suppl. 97, 375-391.

Voorn, P., Vanderschuren, L. J., Groenewegen, H. J., Robbins, T. W., and Pennartz, C. M. (2004). Putting a spin on the dorsal-ventral divide of the striatum. Trends Neurosci. 27, 468-474.

Waldvogel, H. J., Baer, K., Allen, K. L., Rees, M. I., and Faull, R. L. (2007). Glycine receptors in the striatum, globus pallidus, and substantia nigra of the human brain: an immunohistochemical study. J. Comp. Neurol. 502, 1012-1029.

Westerink, B. H., Enrico, P., Feimann, J., and De Vries, J. B. (1998). The pharmacology of mesocortical dopamine neurons: a dual-probe microdialysis study in the ventral tegmental area and prefrontal cortex of the rat brain. J. Pharmacol. Exp. Ther. 285, 143-154.

Westerink, B. H., Kwint, H. F., and deVries, J. B. (1996). The pharmacology of mesolimbic dopamine neurons: a dual-probe microdialysis study in the ventral tegmental area and nucleus accumbens of the rat brain. J. Neurosci. 16, 2605-2611.

Wilson, C. J. (2007). GABAergic inhibition in the neostriatum. Prog. Brain Res. 160, 91-110.

Xi, Z. X., and Stein, E. A. (1998). Nucleus accumbens dopamine release modulation by mesolimbic GABAA receptors-an in vivo electrochemical study. Brain Res. 798, 156-165.

Yadid, G., Pacak, K., Golomb, E., Harvey-White, J. D., Lieberman, D. M., Kopin, I. J., and Goldstein, D. S. (1993). Glycine stimulates striatal dopamine release in conscious rats. $\mathrm{Br}$. J. Pharmacol. 110, 50-53.

Yin, H. H., and Knowlton, B. J. (2004). Contributions of striatal subregions to place and response learning. Learn. Mem. 11, 459-463.

Yin, H. H., Ostlund, S. B., and Balleine, B. W. (2008). Rewardguided learning beyond dopamine in the nucleus accumbens: the integrative functions of cortico-basal ganglia networks. Eur. J. Neurosci. 28, 1437-1448.

Yin, H. H., Park, B. S., Adermark, L., and Lovinger, D. M. (2007). Ethanol reverses the direction of long-term synaptic plasticity in the dorsomedial striatum. Eur. J. Neurosci. 25, 3226-3232. 
Zhou, F. M., Wilson, C. J., and Dani, J. A. (2002). Cholinergic interneuron characteristics and nicotinic properties in the striatum. J. Neurobiol. 53, 590-605.

Conflict of Interest Statement: The authors declare that the research was conducted in the absence of any commercial or financial relationships that could be construed as a potential conflict of interest.

Received: 25 July 2011; accepted: 28 September 2011; published online: 18 October 2011.
Citation: Adermark L, Clarke RBC, Ericson $M$ and Söderpalm B (2011) Subregion-specific modulation of excitatory input and dopaminergic output in the striatum by tonically activated glycine and GABAA receptors. Front. Syst. Neurosci. 5:85. doi: 10.3389/fnsys.2011. 00085
Copyright (C) 2011 Adermark, Clarke, Ericson and Söderpalm. This is an openaccess article subject to a non-exclusive license between the authors and Frontier Media SA, which permits use, distribution and reproduction in other forums, provided the original authors and source are credited and other Frontiers conditions are complied with. 